\title{
Evaluation of pain and flexor reflex responses and their association with clinical parameters in patients with fibromyalgia
}

\author{
Gülsemin Ertürk Çelik (1), Mehmet Beyazova @i \\ Department of Physical Medicine and Rehabilitation, Medicine Faculty of Gazi University, Ankara, Turkey
}

Received: October 11, 2018 Accepted: May 21, 2019 Published online: March 03, 2020

\begin{abstract}
Objectives: In the present study, we aimed to evaluate electrophysiological outcomes of flexor reflexes (FR) emerging in response to painful stimuli in fibromyalgia (FM) patients.

Patients and methods: This study included a total of 21 female FM patients (mean age $36.8 \pm 8.0$ years; range, 20 to 50 years) and 28 healthy female controls (mean age 37.3 \pm 8.8 years; range, 22 to 53 years). Clinical features of the patients, Fibromyalgia Impact Questionnaire (FIQ), Beck Depression Inventory (BDI), and Beck Anxiety Inventory (BAI) scores were recorded. Electrophysiological stimulation threshold, visual analog scale (VAS) scores of generated pain after each stimulation, current intensity, flexor responses obtained from muscles, and electrophysiological measurement of these responses were noted.
\end{abstract}

Results: The threshold for perception of electrical current was higher and resistance level to maximum electrical current was lower in FM patients $(\mathrm{p}<0.05)$. The VAS scores of FM patients under maximum electrical current were higher than the control group ( $\mathrm{p}<0.05)$, while the lowest current value in which FR response obtained in FM patients was lower $(\mathrm{p}<0.05)$. The latency was lower, amplitude was higher, and response area was wider in FM patients $(\mathrm{p}<0.05)$. No significant relationship between the FIQ, BDI, BAI scores and stimulant perception threshold levels was found in FM patients ( $p>0.05)$.

Conclusion: Based on these findings, FR responses may be useful as an electrophysiological parameter in FM diagnosis.

Keywords: Electrophysiology, fibromyalgia, musculoskeletal pain.

Fibromyalgia (FM) is a clinical manifestation characterized by sensitization in specific anatomical regions, chronic diffuse pain, fatigue, sleeping disorders, cognitive function deficits, and depressive episodes. While FM is seen in about $2 \%$ of the adult population, it is much more common among females. It is mostly seen between 30-50 years of age, although it has a wide range of age distribution. ${ }^{[1,2]}$

Despite the fact that FM is a frequently seen chronic pain syndrome in rheumatology practice, its exact etiology and physiopathology are still unknown. Although FM is often considered a muscle disorder, it is also referred as a response to the dysfunction of pain transmission and modulation in the central nervous system (CNS). As pain is the cardinal clinical manifestation in this disorder, most scientific interest is toward pain management. ${ }^{[3]}$

Being one of the cutaneous reflexes, flexor reflex (FR) is composed of coordinated movements for protective and postural functions. It is basically a spinal reflex mechanism generated on sensory afferents as a multi-segmented reflex causing a withdrawal motion when a painful stimulus is applied to skin of the extremity, leading to contraction in flexor muscles. ${ }^{[4]}$

Nociceptive flexion reflex (NFR) is a valuable method in objective detection and quantification of pain threshold. It is a polysynaptic withdrawal reflex which is widely used in experimental and clinical pain trials, and it can be recorded electrophysiologically. These reflexes are also used for the evaluation of the

Corresponding author: Gülsemin Ertürk Çelik, MD. Gençlik ve Spor Bakanlığı, Fiziksel Tıp ve Rehabilitasyon Bölümü, 06090 Altındağ, Ankara, Türkiye.

$$
\text { e-mail: gulseminerturk@gmail.com }
$$


roles of various neurotransmitters' functioning in pain control pathways at spinal and supraspinal levels. In addition, they can be used in altered pain perception and pathophysiology studies of clinical syndromes characterized by chronic pain. ${ }^{[5-7]}$

The diagnosis of FM syndrome is based on the American College of Rheumatology (ACR) classification criteria. ${ }^{[8]}$ The 1990 ACR criteria require chronic widespread pain (CWP) and the presence of $>11$ of 18 specified sites that are tender upon digital palpation. However, the 2010 ACR criteria state that FM is characterized by CWP associated with fatigue, sleep and cognitive disturbances, and a range of somatic symptoms. ${ }^{[9]}$

To date, electrophysiological study of the patients with FM and its contribution to FM diagnosis has not been clearly elucidated. In the present study, we aimed to evaluate electrophysiological outcomes of FR emerging in response to painful stimuli in FM patients.

\section{PATIENTS AND METHODS}

This study included a total of 21 female FM patients (mean age $36.8 \pm 8.0$ years; range, 20 to 50 years) and 28 healthy female controls (mean age $37.3 \pm 8.8$ years; range, 22 to 53 years). The diagnosis of FM was made according to the 1990 ACR criteria. All patients were evaluated in terms of chronic pain, fatigue, sleep disorder, stiffness, paresthesia, headache, irritable bowel syndrome, Raynaud-like symptoms, depression, anxiety, antidepressant usage, and disease duration. Patients with a history of CNS disorders, medication use which can affect the CNS, peripheral neuropathy or radiculopathy, systemic diseases such as diabetes mellitus and coronary artery disease, rheumatological disorders causing muscle and joint pain, abnormal previous laboratory and radiological reports, and pregnancy or trauma were excluded from the study. A written informed consent was obtained from each participant. The study protocol was approved by Ethics Committee of Gazi University Faculty of Medicine (No. 20.06.2005/136). The study was conducted in accordance with the principles of the Declaration of Helsinki.

\section{Outcomes measures}

Eighteen specific tender points were scored in patients using a Likert-type scale (0-3). Specific tender point examination was made by applying a pressure approximately of four $\mathrm{kg}$.
The Turkish version of the Fibromyalgia Impact Questionnaire (FIQ) was used to evaluate patientreported FM severity. ${ }^{[10]}$ The FIQ consists of 20 questions pertaining to morning stiffness, mood, pain, and the ability to perform daily life activity. Scores range from 0 to 100 with a higher value indicating a greater impact of the disorder.

The Beck Depression Inventory (BDI) was used to evaluate depression level. ${ }^{[1]}$ Patients with a BDI score of $\geq 17$ were evaluated in favor of depression.

The Beck Anxiety Inventory (BAI) were applied to FM patients and scores were recorded. ${ }^{[12]}$ It consists of 21 items with a Likert scale ranging from 0 to 3 and raw scores ranging from 0 to 63 . The BAI scores are classified as minimal anxiety (0 to 7), mild anxiety (8 to 15$)$, moderate anxiety (16 to 25$)$, and severe anxiety (30 to 63).

Electrophysiological evaluation was performed with an eight-channel Nihon-Kohden brand ENMG device (Nihon Kohden Corp., America Inc., Irvine, CA, USA). Recordings were made with surface disc electrodes (NE-132B, 2-pin plug, DIN type) in supine position. Four active and four reference electrodes were used for recording. Active electrodes were placed bilaterally, 10 to $12-\mathrm{cm}$ above the popliteal line on the points between the median popliteal line and lateral of the thigh with the participant placed in prone position. Reference electrodes were placed on lateral side of tibial condyles bilaterally. The patient was, then, turned into supine position and electrodes were placed as follows: active electrodes on the tibialis anterior (TA) muscle, four-finger width inferior to the tuberosity of the tibia and reference electrodes to 3 to $4 \mathrm{~cm}$ medial to the muscle on the tibia. Ground electrode was placed on the right lower extremity. Active and reference electrodes were fixed onto the aforementioned points after cleaning the skin with alcohol. Recording electrodes were applied with skin preparation gel (skinPure ${ }^{\oplus}$, Nihon Kohden Corp., America Inc., Irvine, CA, USA) to decrease the skin impedance. Stimulation was applied to the right sural nerve with surface stimulator behind the lateral malleolus (Figure 1).

Following each stimulation, pain revealed according to stimulus magnitude was evaluated with the visual analog scale (VAS). The VAS was scored between 0 and $10(0=$ no pain, $10=$ intense pain). Stimulus intensity was started at $1 \mathrm{~mA}$ and increased by 1 unit until the perceived pain was achieved by the participant and the threshold value was recorded. Afterwards, current intensities at 2-4-6-8-10-12-14-1618-20-22-24 times higher than the threshold value were 


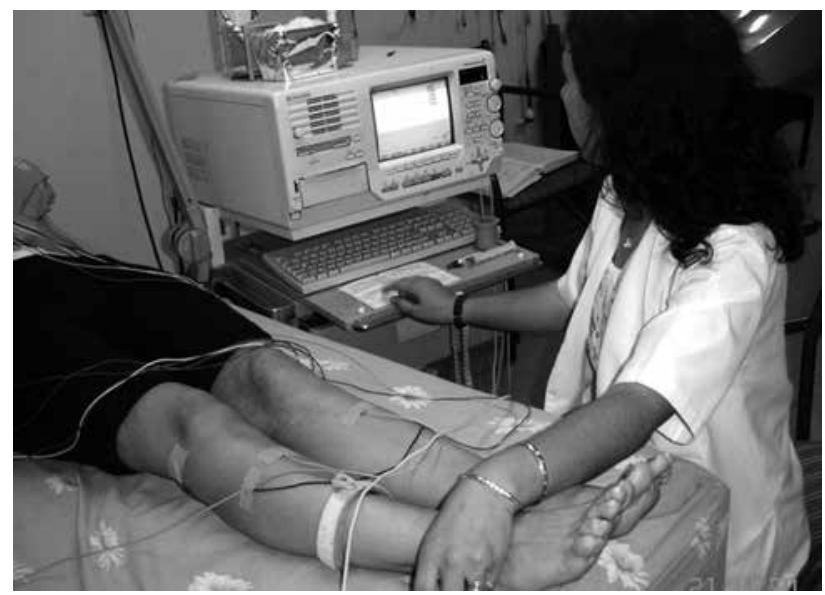

Figure 1. Electrode setup and electro-neuro myelography device.

applied to each participant up to their tolerance limits. Upper limit of the current intensity was accepted as $50 \mathrm{~mA}$, which is the admissible security limit of the ENMG device. Stimuli were applied in an irregular time pattern (5 to $30 \mathrm{sec}$ ) to avoid habitual effect. The procedure was discontinued, when a VAS value of 10 was reached.

The sweep rate was adjusted to $30 \mathrm{msec}$, sensitivity to $500 \mu \mathrm{V}$, high and low filters to $3 \mathrm{kHz}$ and $2 \mathrm{~Hz}$. Stimuli were composed of five rectangular train waves of $90 \mathrm{~Hz}$ frequency and $0.2 \mathrm{msec}$ duration. Bilateral biceps femoris (BF) and tibialis anterior (TA) muscle responses obtained by sural nerve stimulation were recorded to the hard disc of the ENMG device. Once the threshold was detected, the values were multiplied by the aforementioned multipliers to calculate the current intensity to be applied. The study was terminated, when a VAS score of 10 or maximum current intensity was reached.

After all recordings were completed, data were evaluated. If the FR response was obtained, the latency, amplitude and area measurements were made. Area measurements were made by rectifying the responses from all four muscles. Latency was defined as the first deflection point from the isoelectric line, amplitude was defined as the value between lowest and highest peaks, and area measurement was automatically made by the device by marking starting and ending points of the rectified responses. Responses with amplitude less than $10 \%$ of the maximum amplitude and with latency shorter than $20 \mathrm{msec}$ were not accepted as reflex responses.

\section{Statistical analysis}

The power analysis for the estimation of the sample size was unable to be performed; however, the post-hoc power analysis using the $\mathrm{G}^{\star}$ Power $^{\odot} 3.1$ program (Heinrich-Heine-Universität Düsseldorf, Düsseldorf, Germany) was performed. The present study primarily compared maximum tolerable current intensity in 21 FM patients and 28 healthy controls. The post-hoc power analysis using the Wilcoxon-Mann-Whitney test for two groups revealed an effect size of d:3.21 and the power of the study was calculated as $100 \%$ with $5 \%$ type 1 error.

\begin{tabular}{|c|c|c|c|c|}
\hline \multicolumn{5}{|c|}{$\begin{array}{c}\text { TABLE } 1 \\
\text { Clinical features of FM patients }\end{array}$} \\
\hline & $\mathrm{n}$ & $\%$ & Median & Min-Max \\
\hline Chronic generalized pain & 21 & 100 & & \\
\hline Fatigue & 21 & 100 & & \\
\hline Paresthesia & 19 & 90.5 & & \\
\hline Headache & 19 & 90.5 & & \\
\hline Sleeping disorder & 17 & 81 & & \\
\hline Morning stiffness & 15 & 71.4 & & \\
\hline Irritable bowel syndrome & 14 & 66.7 & & \\
\hline Raynaud like symptoms & 14 & 66.7 & & \\
\hline Depression history & 9 & 42.9 & & \\
\hline Anxiety history & 6 & 28.6 & & \\
\hline FIQ score median & & & 66.48 & $43.8-94.9$ \\
\hline BAI score median & & & 27 & $16-51$ \\
\hline BDI score median & & & 17 & $8-35$ \\
\hline
\end{tabular}




\begin{tabular}{|c|c|c|c|c|c|}
\hline \multicolumn{6}{|c|}{$\begin{array}{c}\text { TABLE } 2 \\
\text { Stimulus perception thresholds, maximum applied current intensity, and VAS at maximum current intensity } \\
\text { between groups }\end{array}$} \\
\hline & \multicolumn{2}{|c|}{ Fibromyalgia $(\mathrm{n}=21)$} & \multicolumn{2}{|c|}{ Control $(\mathrm{n}=28)$} & \multirow[b]{2}{*}{$p$} \\
\hline & Median & Min-Max & Median & Min-Max & \\
\hline Stimulus perception threshold (mA) & 2 & $2-3$ & 4 & $3-6$ & $<0.01$ \\
\hline Maximum tolerable current intensity (mA) & 20 & $12-40$ & 48 & $24-50$ & $<0.01$ \\
\hline VAS score at maximum current intensity & 10 & 10 & 8 & $0-10$ & $<0.01$ \\
\hline Lowest current intensity which generated FR (mA) & 20 & $12-40$ & 48 & $24-50$ & $<0.01$ \\
\hline
\end{tabular}

Statistical analysis was performed using the SPSS version 11.0 software (SPSS Inc., Chicago, IL, USA) and Minitab version 13.1 package program (Minitab ${ }^{\bullet}$ Statistical Software, LLC, PA USA). Descriptive data were expressed in mean \pm standard deviation (SD), median (min-max), or number and frequency. The ratio of formation of FR response in all four muscles and VAS scores at 2, 4, 6, 8, 10, 12, 14, 16, 18, 20, 22 multiples of perception threshold were compared using the $\mathrm{Z}$ test with Minitab 13.1 software. Normality

(a)

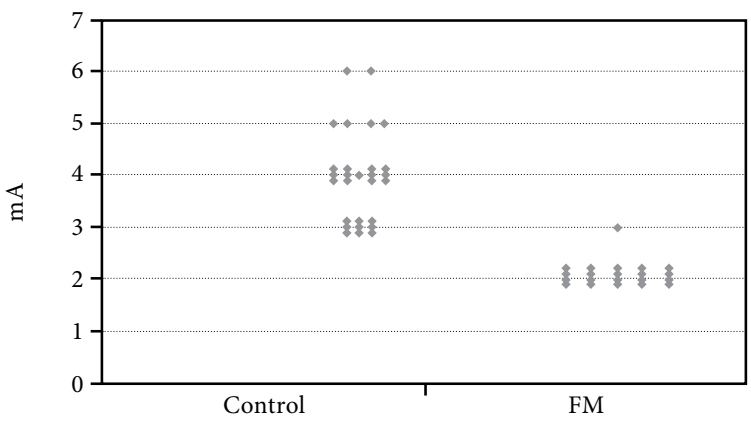

(c)

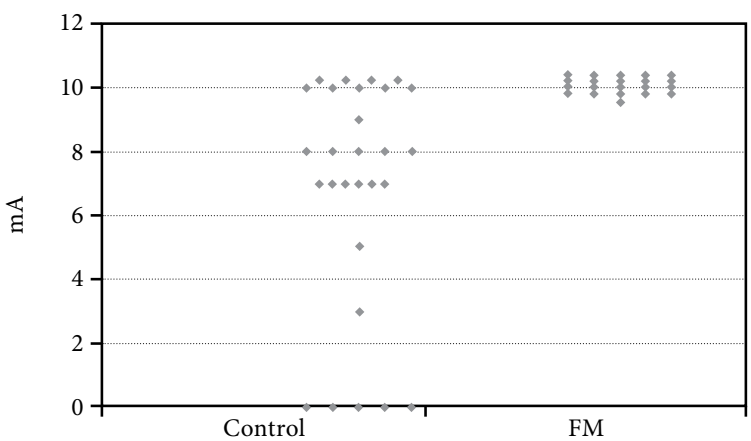

of data was analyzed using the Kolmogorov-Smirnov test. The FIQ, BDI and BAI levels of FM patients were calculated using the Spearman correlation coefficient. Numeric parametric data were analyzed using the Student's t-test, while non-numeric data were analyzed using the chi-square test. The Mann-Whitney U test was used to compare stimulus perception threshold values, current intensity values of $2,4,6,8,10,12,14,16,18,20,22$ folds of the threshold value, VAS scores at these current

(b)

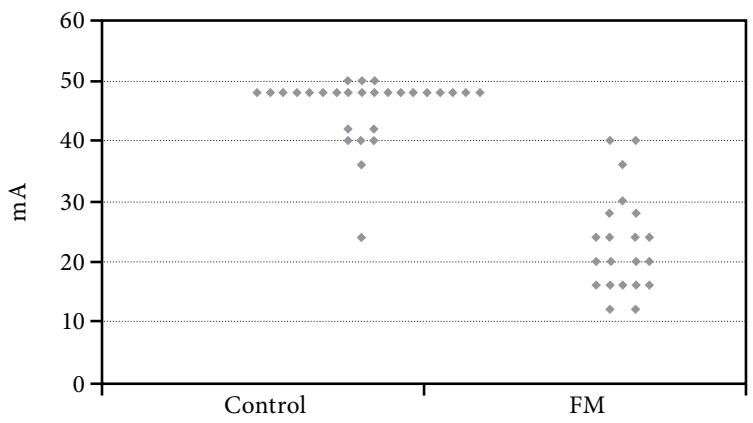

(d)

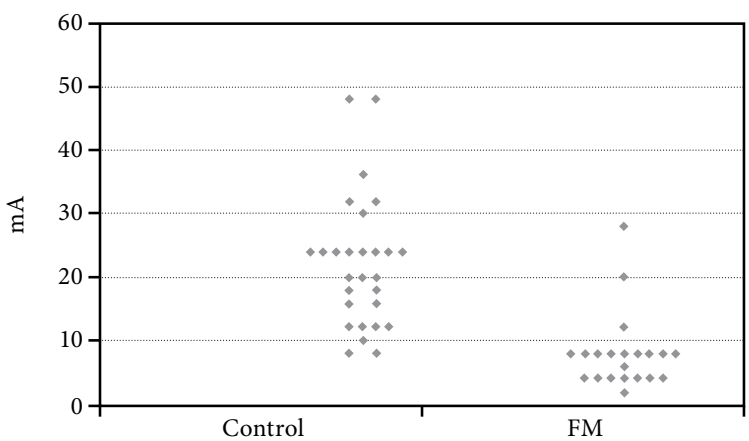

Figure 2. Comparison of stimulus perception threshold, tolerable maximum current intensity, VAS scores at maximum current intensity, and lowest current intensity at which flexor reflex was obtainable among study groups. (a) Stimulus perception threshold. (b) Tolerable maximum current intensity. (c) VAS scores. (d) The lowest current intensity to obtain flexor reflex.

VAS: Visual analog scale; FM: Fibromyalgia. 
intensities, and minimum current intensity needed to obtain a FR response in the patient and control groups. The Mann-Whitney $U$ test was also used to compare latency, amplitude, and area measurements of obtained FR responses from BF and TA muscles at maximum current intensity between patient and control groups. A $p$ value of $<0.05$ was considered statistically significant.

\section{RESULTS}

There was no significant difference in the age and sex between the patient and control groups. Clinical characteristics of the FM patients are shown in Table 1.

The threshold for perception of painful stimulus and maximum applicable current intensities of FM patients were significantly lower $(\mathrm{p}<0.01)$ and VAS scores at maximum stimulus levels were significantly higher than controls $(\mathrm{p}<0.01)$. The lowest current intensity at which FR emerged was significantly lower in the FM group $(\mathrm{p}<0.01)$ (Table 2, Figure 2).

While the FR development frequency was significantly higher in the patient group at 2 and 4 multiples of threshold value in the same and opposite side muscles $(\mathrm{p}<0.05)$, there was no significant difference at higher current intensities between the groups $(p>0.05)$. Increasing the current intensity at the same side, TA muscle caused an increase in the FR formation ratio at all intensity levels in the patient group; however, no FR formation was observed in the control group. At the opposite side muscle, no FR was observed in the control group at 2, 4 and 16 multiples of current intensity; and at $6,8,10,12$, and 14 multiples of intensity, the FR formation ratio in the patient group was significantly higher $(\mathrm{p}<0.05)$ (Table 3$)$.

Latency was shorter, amplitude was lower, and area was wider bilaterally in BF muscles $(\mathrm{p}<0.05)$. No FR emerged in the same side TA muscles of healthy controls. No significant difference was observed in the opposite site TA muscles between the groups ( $>0.05$ ) (Table 4).

Correlation analysis revealed no significant relationship between the FIQ, BDI, and BAI scores of FM patients and stimulus perception threshold values (p>0.05) (Table 5).

\section{DISCUSSION}

In the current study, we performed electrophysiological evaluation of the FR emerging

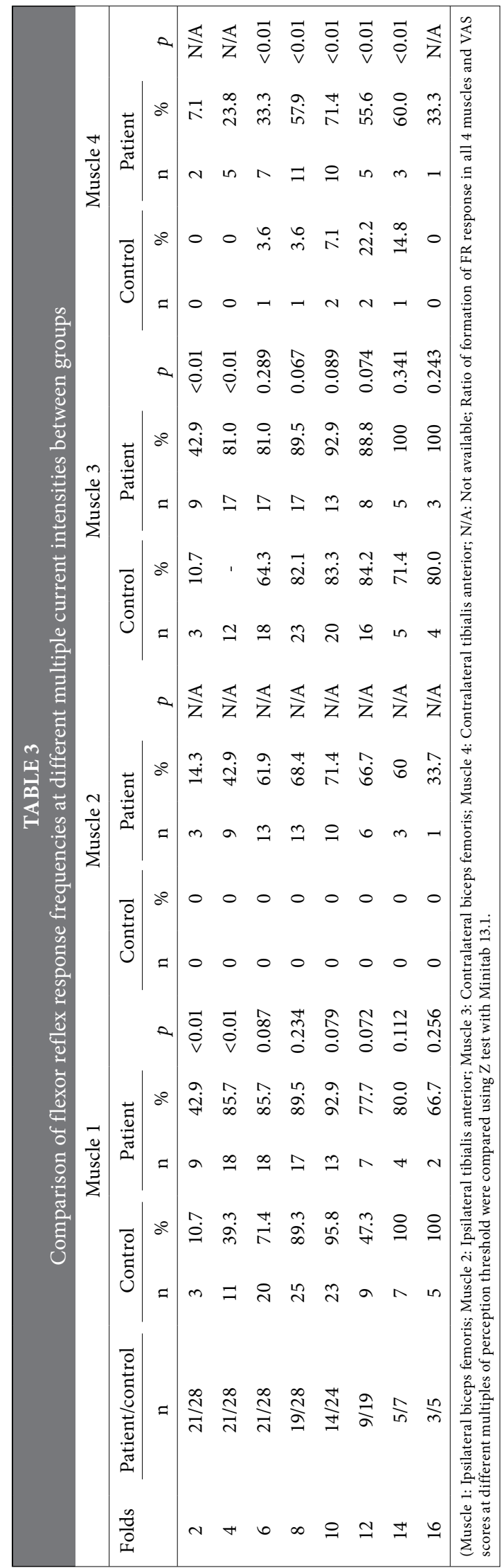




\begin{tabular}{|c|c|c|c|c|c|c|c|}
\hline \multicolumn{8}{|c|}{ Comparison of latency, amplitude and area measurem } \\
\hline & \multicolumn{3}{|c|}{ Patient $(\mathrm{n}=21)$} & \multicolumn{3}{|c|}{ Control $(n=28)$} & \multirow[b]{2}{*}{$p$} \\
\hline & $\mathrm{n}$ & Median & Min-Max & $\mathrm{n}$ & Median & Min-Max & \\
\hline \multicolumn{8}{|l|}{ Latency (msn) } \\
\hline Ipsilateral biceps femoris & 21 & 64 & $22-108$ & 27 & 82 & $42-134$ & $<0.01$ \\
\hline Ipsilateral tibialis anterior & 18 & 96 & $44-200$ & 0 & & & N/A \\
\hline Contralateral biceps femoris & 21 & 90 & $50-140$ & 26 & 114 & $72-154$ & 0.043 \\
\hline Contralateral tibialis anterior & 17 & 120 & $80-150$ & 2 & & $114-134$ & 0.083 \\
\hline \multicolumn{8}{|l|}{ Amplitude (mV) } \\
\hline Ipsilateral biceps femoris & 21 & 1.5 & $0.27-4.4$ & 27 & 0.8 & $0.2-4.1$ & 0.042 \\
\hline Ipsilateral tibialis anterior & 18 & 0.8 & $0.1-3.6$ & 0 & & & N/A \\
\hline Contralateral biceps femoris & 21 & 1.6 & $0.4-3.2$ & 26 & 0.9 & $0.2-3.5$ & 0.041 \\
\hline Contralateral tibialis anterior & 17 & 0.6 & $0.1-1$ & 2 & & $0.35-0-47$ & 0.082 \\
\hline \multicolumn{8}{|l|}{ Area } \\
\hline Ipsilateral biceps femoris & 21 & 48.2 & $5.4-106.7$ & 27 & 20.2 & $8.1-162$ & 0.039 \\
\hline Ipsilateral tibialis anterior & 18 & 14.6 & 4.7-37.9 & 0 & & & $\mathrm{~N} / \mathrm{A}$ \\
\hline Contralateral biceps femoris & 21 & 38.4 & $14.8-95.6$ & 26 & 14.7 & $3.4-87.6$ & 0.046 \\
\hline Contralateral tibialis anterior & 17 & 8.6 & $3.5-26.9$ & 2 & & $4.9-10.6$ & 0.171 \\
\hline
\end{tabular}

in FM patients in response to painful stimuli and compared these reflexes with those of healthy individuals. Our study results demonstrated that perception of painful stimulus threshold was very low and pain scores tended to increase with the increasing stimulus intensity in FM patients. More importantly, there were significant differences in pain perception and flexor muscle responses to pain, compared to healthy volunteers. It is considered that central sensitivity develops in this disease due to neuroplastic alterations. ${ }^{[13]}$ To the best of our knowledge, FR as an electrophysiological parameter in FM has not been fully investigated, yet.

\begin{tabular}{|cc|}
\hline \multicolumn{2}{|c|}{ TABLE 5 } \\
Correlation analysis results \\
\hline Beck anxiety inventory \\
r \\
p & -0.333 \\
Fibromyalgia impact questionnaire & 0.141 \\
r & \\
p & -0.332 \\
Beck depression inventory & 0.141 \\
r & -0.370 \\
p & 0.099 \\
\hline Spearman's correlation coefficient test was used for correlation analysis. \\
\hline
\end{tabular}

It has been shown by previous studies that the most common symptoms seen in FM patients are generalized body pain and fatigue, followed by paresthesia and headache. ${ }^{[4-18]}$ Consistent with the literature, generalized pain and fatigue were observed in all our patients, and paresthesia, headache and sleeping disorders were present in the majority of the patients. We believe that these symptoms are inter-related and that is why they are seen at high ratios in FM patients.

In previous studies, depression and anxiety were reported in 14 to $70 \%$ of FM patients and the FIQ, BDI, and BAI scores were found to be higher in these patients. ${ }^{[13,17-20]}$ Desmeules et al. ${ }^{[13]}$ reported that depression and anxiety decreased physiological movements due to the psychophysical nature of FM. Depression and anxiety ratios in our study are also consistent with the literature. We believe that the FIQ scores decreased as the individual felt pain, leading to depression and anxiety. Besides this, anxiety and depression may have negatively influenced the FIQ scores over time through negative feedback mechanism.

It has been shown that central sensitization mechanisms play an important role in chronic pain development. ${ }^{[6,7,21,22]}$ Reactions against painful stimuli are protective and a reflex response is generated 
to prevent an injury. Recurrent stimuli decrease the activation threshold and a stronger response to upcoming input is formed, leading to the sensitization of the protective nociceptive system. ${ }^{[21,22]}$ Studies of Banic et al. ${ }^{[23]}$ and Desmeules et al. ${ }^{[13]}$ showed that FM patients had lower excitement thresholds. Latremoliere and Woolf ${ }^{[22]}$ also reported that membrane excitement was easier, synaptic activity increased, and inhibition ratio decreased in FM patients. In our study, we found that patients with FM had a lower threshold for perception of electric current and the peak value of current intensity they could endure was lower than normal control group. This can be explained by spinal hypersensitivity and hyperexcitability of the CNS.

Central sensitization is known to play a key role in the abnormal pain development in FM and these patients have an exaggerated sensitivity to mechanical pressure and heat. ${ }^{[22,24-29]}$ It has been well established that $\mathrm{C}$ filaments are defective in FM patients, which function in pain transmission, and the main pathology is increased cellular calcium levels which affects excitability via capsaicin, leading to hyperalgesia and allodynia. ${ }^{[22,28]}$ In studies evaluating this effect, VAS score was found significantly to be higher in FM patients where pain intensity was analyzed. ${ }^{[30,31]}$ In our study, we found out that VAS values of FM patients were higher at maximum current intensity, compared to controls, and VAS scores also increased with the stimulus intensity. This can be attributed to spinal hypersensitivity, exaggerated perception of painful stimuli, and also perception of a non-painful stimulus as a painful one. In addition, perception of pain in FM without any tissue injury can be explained by the hyperexcitability of the CNS, leading to chronic painful situations.

In their study, Sörensen et al. ${ }^{[32]}$ found central hyperexcitability in the nociceptive system and lowering of pain threshold due to excitation of intramuscular nociceptors in FM patients. In the present study, the lowest current intensity to obtain a FR response was found to be lower in FM patients, compared to the control group. This situation reflects the central hyperexcitability in the nociceptive system in FM patients, suggesting that FR can be used to evaluate central allodynia in FM.

In previous studies carried out with capsaicin injection, a hypersensitive unmodified facilitated heterosynaptic region formation was observed around the injection area. ${ }^{[2,33,34]}$ Furthermore, a relationship between the reflex formation and pain perception was shown. ${ }^{[35]}$ In our study, FR response was obtained bilaterally from the BF muscles in the control group, while no FR response was obtained from the ipsilateral TA muscles. In only two participants, weak responses were obtained by high current stimulations from the contralateral TA muscles. On the contrary, in FM patients, strong FR responses were obtained at low current intensities on bilateral $\mathrm{BF}$ and $\mathrm{TA}$ muscles. Additionally, the frequency of FR responses obtained in patient and control groups increased as current intensity increased and, above a certain value, a decrease in response was observed without any significant difference between the groups. We also believe that FR may emerge in other extremities in response to allodynia. In addition, in both groups, no FR may be generated due to blocking of mediator release into synaptic junctions over a certain stimulus intensity. Withdrawal of patients who could not tolerate the high intensity currents for reflex formation might also have affected the high intensity results in our study.

It has been reported that in patients who developed central sensitization due to the sensitization of dorsal spinal neurons, increased spontaneous activity, decreased threshold time, overstimulation response, and widened receptive area occurs. ${ }^{[22,36,37]}$ Consistent with previous data, we believe that latency is shorter, amplitude is higher, and response area is wider in FM patients due to increased hypersensitivity in the spine and interneuronal communication. Rapid stimulated and long duration action potential formation caused by hypersensitivity may be also a fact in these patients.

A combination of factors such as sensitivity, time, place, and threshold value is held responsible for the level of pain in patients with central sensitization. ${ }^{[22]}$ Low latency, high amplitude, and lower stimulation threshold have been shown in FM patients with depression in a previous study; however, its clinical relevance was not evaluated. ${ }^{[28]}$ Crettaz et al. ${ }^{[38]}$ reported that pain increased in response to pressure in FM patients by increased psychological stress. Coppieters et al. ${ }^{[39]}$ also showed that both psychological and physiological changes were effective in pain generation in FM. In our study, no significant relationship between the FIQ, BDI, and BAI scores and stimulus perception threshold in FM patients was found. Lack of data about psychological status of patients during study might have caused a restriction in interpretation of relationship between FM and the FIQ, BDI, and BAI. This situation might be also caused by the limited number of cases included in the study. 
There are some limitations to this study. First, we used 1990 ACR criteria for FM diagnosis, as the study was held before the new criteria were published. Second, we were unable to perform power analysis for the estimation of sample size, although we performed post-hoc power analysis.

In conclusion, the responses given to applied current levels are different in FM patients, compared to healthy individuals. This finding indicates that NFR evaluations may make a contribution to FM diagnosis. Currently, clinically used diagnostic tools for FM is mainly based on tender points, CWP associated with fatigue, sleep and cognitive disturbances, and a range of somatic symptoms. Electrophysiological studies may be both useful for FM diagnosis and to delineate the involvement of neural tissue in FM. However, further studies are warranted to confirm our findings and to evaluate diagnostic and/or prognostic value of other electrophysiological parameters in patients with FM.

\section{Declaration of conflicting interests}

The authors declared no conflicts of interest with respect to the authorship and/or publication of this article.

\section{Funding}

The authors received no financial support for the research and/or authorship of this article.

\section{REFERENCES}

1. Coşkun NC. Clinical Manifestations, Diagnosis and Differential Diagnosis of Fibromyalgia Syndrome. Turkiye Klinikleri J PM\&R-Special Topics 2015;8:15-21.

2. Ata AM, Çetin A. Definition of Fibromyalgia, its Epidemiology. Turkiye Klinikleri J PM\&R-Special Topics 2015;8:1-4

3. Markkula RA, Kalso EA, Kaprio JA. Predictors of fibromyalgia: a population-based twin cohort study. BMC Musculoskelet Disord 2016;17:29.

4. Pearson K, Gordon J. Spinal reflexes In: Kandel ER, Schwartz JH, Jessell TM, editors. Principles of Neural Science. 4th ed. New York: McGraw-Hill Companies; 2005. p. 713-37.

5. Lichtner G, Golebiewski A, Schneider MH, von Dincklage F. Introduction and validation of a less painful algorithm to estimate the nociceptive flexion reflex threshold. Brain Res 2015;1608:147-56.

6. Neziri AY, Haesler S, Petersen-Felix S, Müller M, ArendtNielsen L, Manresa JB, et al. Generalized expansion of nociceptive reflex receptive fields in chronic pain patients. Pain 2010;151:798-805.

7. Biurrun Manresa JA, Nguyen GP, Curatolo M, Moeslund TB, Andersen OK. Probabilistic model for individual assessment of central hyperexcitability using the nociceptive withdrawal reflex: a biomarker for chronic low back and neck pain. BMC Neurosci 2013;14:110.
8. Wolfe F, Smythe HA, Yunus MB, Bennett RM, Bombardier C, Goldenberg DL, et al. The American College of Rheumatology 1990 Criteria for the Classification of Fibromyalgia. Report of the Multicenter Criteria Committee. Arthritis Rheum 1990;33:160-72.

9. Wolfe F, Clauw DJ, Fitzcharles MA, Goldenberg DL, Katz RS, Mease P, et al. The American College of Rheumatology preliminary diagnostic criteria for fibromyalgia and measurement of symptom severity. Arthritis Care Res (Hoboken) 2010;62:600-10.

10. Sarmer S, Ergin S, Yavuzer G. The validity and reliability of the Turkish version of the Fibromyalgia Impact Questionnaire. Rheumatol Int 2000;20:9-12.

11. Hisli N. Beck depresyon envanterinin geçerliliği üzerine bir çalışma. Psikoloji Dergisi 1988;22:118-26.

12. Beck AT, Epstein N, Brown G, Steer RA. An inventory for measuring clinical anxiety: psychometric properties. J Consult Clin Psychol 1988;56:893-7.

13. Desmeules JA, Cedraschi C, Rapiti E, Baumgartner E, Finckh A, Cohen P, et al. Neurophysiologic evidence for a central sensitization in patients with fibromyalgia. Arthritis Rheum 2003;48:1420-9.

14. Hayta E, Doğan Ö, Doğan SC, Akdeniz T, Şencan D, Karakaşlı S, et al. Fibromiyalji tanısı konan 100 kadın olgunun klinik özellikleri. Cumhuriyet Medical Journal 2010;32:74-9.

15. Bradley LA, Alarcon GS. Fibromyalgia. In Koopman WJ, editor. Arthritis and Allied Conditions a Textbook of Rheumatology. Philedelphia: Lippincott Williams \& Wilkins; 2001. p. 1811-44.

16. Mease P. Fibromyalgia syndrome: review of clinical presentation, pathogenesis, outcome measures, and treatment. J Rheumatol Suppl 2005;75:6-21.

17. Celiker R, Borman P, Oktem F, Gökçe-Kutsal Y, Başgöze O. Psychological disturbance in fibromyalgia: relation to pain severity. Clin Rheumatol 1997;16:179-84.

18. Akyol Y, Ulus Y, Tander B, Bilgici A, Kuru O. Muscle Strength, Fatigue, Functional Capacity, and Proprioceptive Acuity in Patients With Fibromyalgia. Turk J Phys Med Rehab 2013;59:292-8.

19. Sayar K, Aksu G, Ak I, Tosun M. Venlafaxine treatment of fibromyalgia. Ann Pharmacother 2003;37:1561-5.

20. Ji RR, Kohno T, Moore KA, Woolf CJ. Central sensitization and LTP: do pain and memory share similar mechanisms? Trends Neurosci 2003;26:696-705.

21. Nijs J, Van Houdenhove B, Oostendorp RA. Recognition of central sensitization in patients with musculoskeletal pain: Application of pain neurophysiology in manual therapy practice. Man Ther 2010;15:135-41.

22. Latremoliere A, Woolf CJ. Central sensitization: a generator of pain hypersensitivity by central neural plasticity. J Pain 2009;10:895-926.

23. Banic B, Petersen-Felix S, Andersen OK, Radanov BP, Villiger PM, Arendt-Nielsen L, et al. Evidence for spinal cord hypersensitivity in chronic pain after whiplash injury and in fibromyalgia. Pain 2004;107:7-15.

24. Ablin J, Neumann L, Buskila D. Pathogenesis of fibromyalgia - a review. Joint Bone Spine 2008;75:273-9. 
25. Staud R, Bovee CE, Robinson ME, Price DD. Cutaneous C-fiber pain abnormalities of fibromyalgia patients are specifically related to temporal summation. Pain 2008;139:315-23.

26. Woolf CJ. Central sensitization: implications for the diagnosis and treatment of pain. Pain 2011;152:S2-15.

27. Curatolo M. Diagnosis of altered central pain processing. Spine (Phila Pa 1976) 2011;36:S200-4

28. Üçeyler N, Zeller D, Kahn AK, Kewenig S, Kittel-Schneider S, Schmid A, et al. Small fibre pathology in patients with fibromyalgia syndrome. Brain 2013;136:1857-67.

29. Blumenstiel K, Gerhardt A, Rolke R, Bieber C, Tesarz J, Friederich HC, et al. Quantitative sensory testing profiles in chronic back pain are distinct from those in fibromyalgia. Clin J Pain 2011;27:682-90.

30. Laursen BS1, Bajaj P, Olesen AS, Delmar C, Arendt-Nielsen L. Health related quality of life and quantitative pain measurement in females with chronic non-malignant pain. Eur J Pain 2005;9:267-75.

31. Bigatti SM, Cronan TA. A comparison of pain measures used with patients with fibromyalgia. J Nurs Meas 2002;10:5-14.

32. Sörensen J, Graven-Nielsen T, Henriksson KG, Bengtsson M, Arendt-Nielsen L. Hyperexcitability in fibromyalgia. J Rheumatol 1998;25:152-5.

33. Willis WD. Long-term potentiation in spinothalamic neurons. Brain Res Brain Res Rev 2002;40:202-14.
34. Torebjörk HE, Lundberg LE, LaMotte RH. Central changes in processing of mechanoreceptive input in capsaicininduced secondary hyperalgesia in humans. J Physiol 1992;448:765-80.

35. Sandrini G, Serrao M, Rossi P, Romaniello A, Cruccu G, Willer JC. The lower limb flexion reflex in humans. Prog Neurobiol 2005;77:353-95.

36. Woolf CJ. Central sensitization: uncovering the relation between pain and plasticity. Anesthesiology 2007;106:864-7.

37. Svensson CI, Marsala M, Westerlund A, Calcutt NA, Campana WM, Freshwater JD, et al. Activation of p38 mitogen-activated protein kinase in spinal microglia is a critical link in inflammation-induced spinal pain processing. J Neurochem 2003;86:1534-44.

38. Crettaz B, Marziniak M, Willeke P, Young P, Hellhammer D, Stumpf A, et al. Stress-induced allodynia--evidence of increased pain sensitivity in healthy humans and patients with chronic pain after experimentally induced psychosocial stress. PLoS One 2013;8:e69460.

39. Coppieters I, Cagnie B, Nijs J1, van Oosterwijck J, Danneels L, De Pauw R, et al. Effects of Stress and Relaxation on Central Pain Modulation in Chronic Whiplash and Fibromyalgia Patients Compared to Healthy Controls. Pain Physician 2016;19:119-30. 